\title{
أساليب تعلم الأطفال من الميلاد حتى سن الثالثة
}

\author{
إعداد \\ د.محمد خليفة إسماعيل متولي \\ رئيس مجلس أمناء مؤسسة تربية الطفولة المبكرة
}

يتعلم الرضع، مثل جميع الأطفال الصغار، عن طريق الاستكثاف النشط لبيئتهم، وهو ما يطلق عليه" التعلم النشط" . ووفقاً (French and)

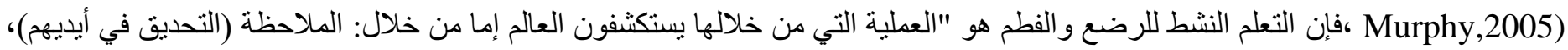

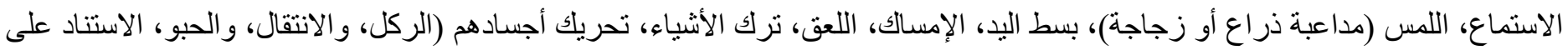

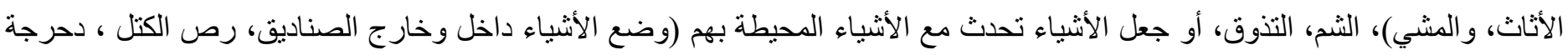

"الكرة)

إن بيئة التعلم النشط تبني الثقة والاستقلال و المبادرة في الأطفال الصغار. لضمان أن الرضع و الفطم يستمتعون بهذه الفو ائد وينجحون في مركز الر عاية البرنامج، يوجد خمسة عناصر للتعلم النشطو هي بمثابة توجيهات عملية للحاضنات: 1. الأدوات:

توجد أدوات بوفرة مناسبة عمريا يستطيع الطفل استخدامها بطرق متعددة. يتطور التعلم مباشرة من تصرفات الطفل المباشرة مع الأدوات.

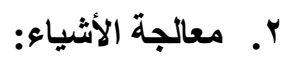

يتو افر لاى الطفل فرص للاستكشاف (بكافة الحواس)، و المعالجة، و الدمج، وتحويل الأدو ات المختارة.

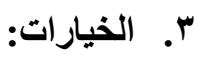

يختار الطفل ما يقوم به، و ينتج التعلم عن محاو لات الطفل لتحقيق المصالح الثخصية والأهداف، لذلك من الضروري تو افر فرص لاختيار الأنشطة و الأدوات.

؛. تواصل الطقل واللغة والتفكير:

يقوم الطفل بتوصيل احتياجاته و مشاعره و اكتشافاته و أفكاره من خلال الحركات، و الإيماءات، وتعبيرات الوجه، والأصوات، ولغة الإشارة، و الكلمات. و على مقدمات الر عاية تقدير والانتباه إلى وتتجيع تو اصل الطفل و واللغة بشكل متبادل.

•. . توفير أدوات مقدمات الرعاية:

تقوم مقدمات الر عاية بتكوين و الحفاظ على علاقات قائمة على الثقة مع كل طفل. يدرك مقدمات الرعاية ويشجعون نو ايا، وتصرفات، وتفاعلات، ونو اصل، و استكشافات، وحل مشكلات، و إبداع كل طفل.

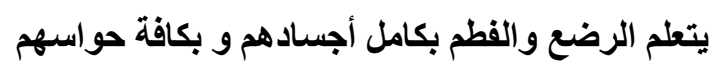
يقوم الرضع و الفطم بجمع معلوماتهم عند كل تصرف ـ ـ بالتحديق في وجه الأم أو مقدمة الرعاية، اللعب بأيديهم، لمس الزجاجة، قلب الكوب،

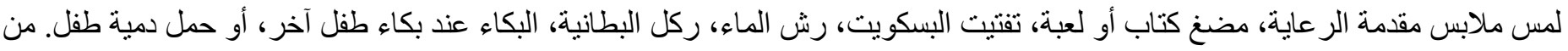
خلال التآزر بين التذوق واللمس و الثم و الرؤية والأصوات والثعور و الأفعال، فإنهم قادرون على بناء المعرفة. استخدم عالم نفس التطور جان 
بياجيه Jean Piaget مصطلح "الحسي حركي " لوصف هذا الاتجاه المباثر الجسمي للتعلم. يشير مفهوم الحسي إلى طريقة جمع الرضع و الفطم للمعلومات عن العالم من خلال كافة حو اسهم؛ أما حركي تشير إلى طريقة تعلمهم من خلال الحركة الجسمية. تؤكد الأبحاث المستمرة على الدماغ مدى ملاءمة مصطلح بياجيه Piaget. يتطور دماغ الرضيع في شكل "موجات، مع أجزاء مختلفة من الدماغ

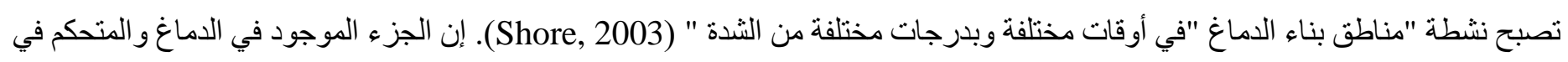

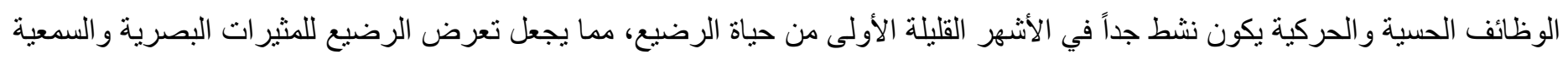

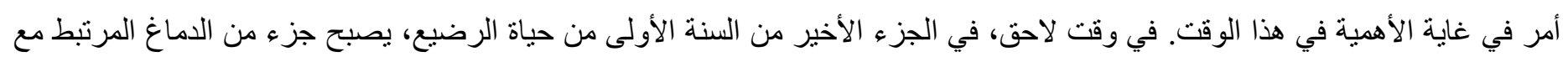

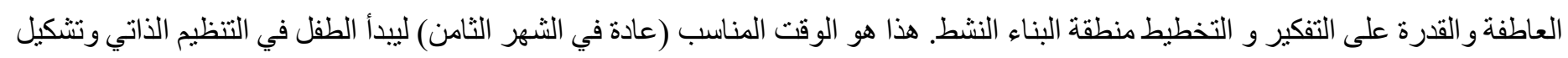
علاقات قوية مع مقدمة الرعاية الرئيسية له.

Meltzoff, Kuhl, Movellan, \& Sejnowski, ) يتعلم الرضع و الفطم بالممارسة لأن أدمغتهم الصغيرة استعدت لربط الفعل بالإدر الك الحسي

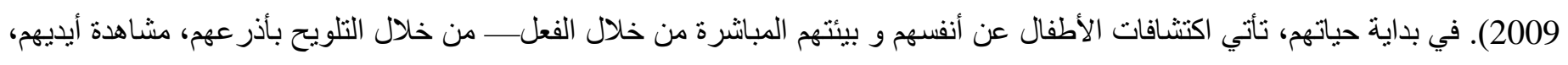

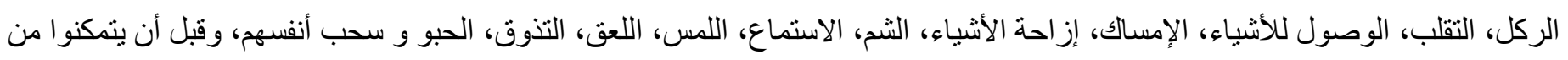

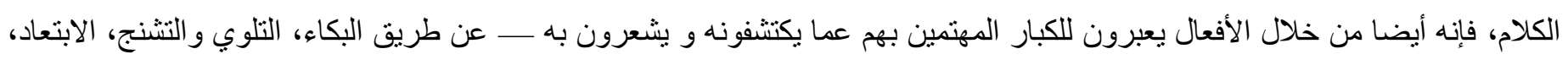

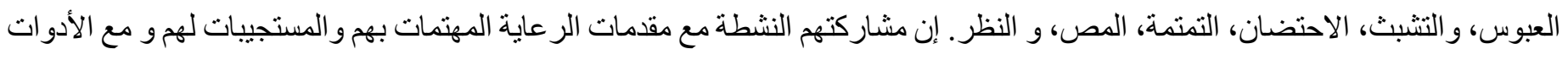

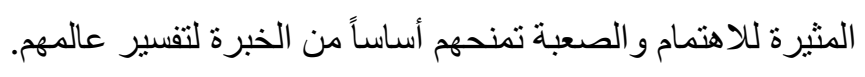

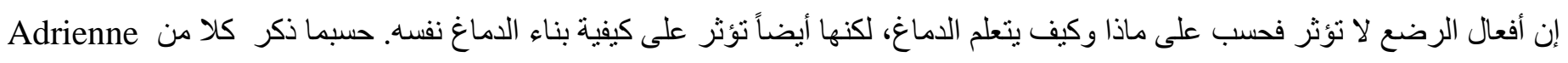
( Tierney \& Charles Nelson,2009)

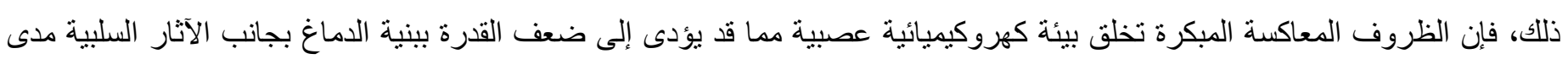

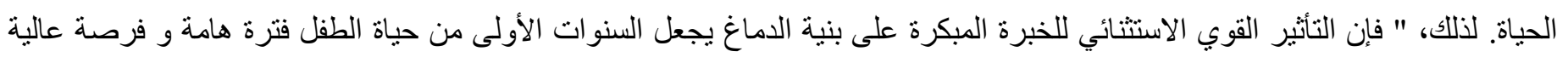

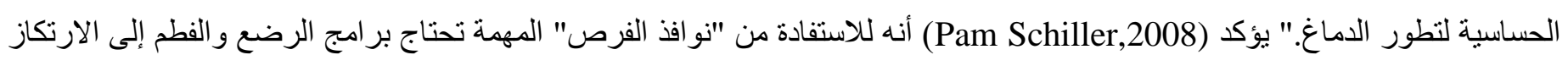
على أبحاث الدماغ وتوفير خبر ات تدعم بوضوح اللغة، التطور الحركي، الاجتماعي ، و التطور الوجداني و المعرفي.

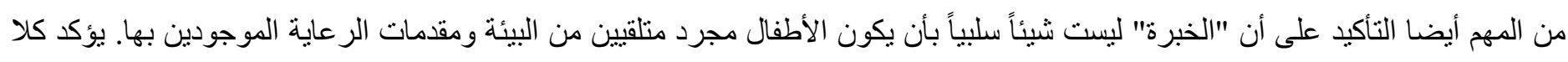
من (Tierney \& Nelson,2009) أن الخبرة، لا نقصد بها الأحداث و الظروف التي تحدث ببساطة في حياة الفرد؛ ولكننا نُعرّف الخبرة بأنها التفاعل بين الفرد وبيئته. كذلك يرى Tierney \& Nelson ، أن الأطفال الصغار هم عو امل فاعلة في صياغة خبر اتهم. على سبيل المثال، إنهر

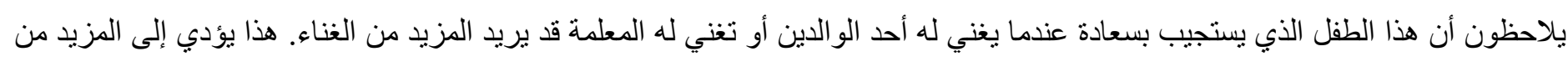

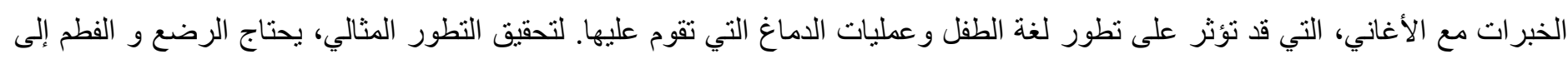

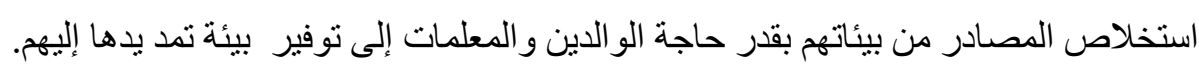

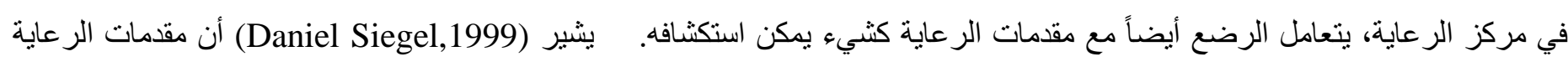

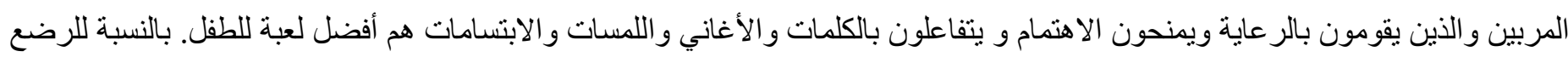
و الفطم، هي كل شيء مثير للاهتمام مثل العديد من الأشياء و الألعاب الأخرى و عموما أكثر استجابة! لهذا السبب يقوم الرضع بدر اسة وجنه ونه مقدمة الرعاية، يستمعون إليها ويستجييون لنبرة صوتها، يعرفون رائحتها، ويشعرون بالر احة على ذر اعها وجسمها. يقوم الفطم باستغلال مقدمات

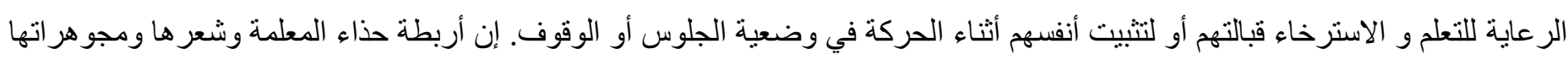
ونظارتها وملابسها توفر مجمو عة متتوعة من الملمس والألوان التي يلمسونها ويمسكون بهاء 
تشكل زيادة الحركة خبرات تعلم جديدة. عندما يتعلم الأطفال الجلوس دون مساعدة، فإنهم يجدون أن لايهم حرية أكبر لرؤية الأشياء والوصول إليها و التعامل معها. كلما سنحت الفرصة للرضع المتحركين بالحبو ودفع أنفسهم لأعلى والتسلق على أب سطح جذاب. يستمتع الفطم بالتوازن

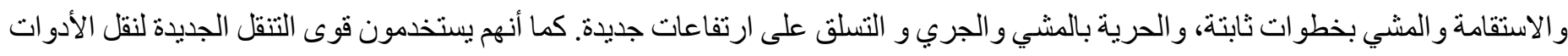
من مكان إلى آخر. إنهم يقومون بسحب ودفع العربات ولعب الأراجيح وسحب الكراسي أو صناديق كبيرة إلى مكان مر غوب أكثر. قد يحاولون

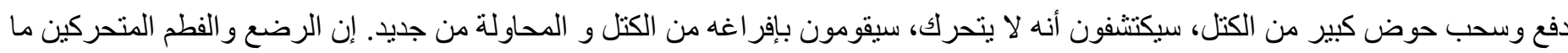
هم إلا أدو ات و ألعاب متحركة.

يتفاعل الرضع و الفطم مع الأشخاص ويتعاملون مع الأدوات، إنهم يشكلون مرجع من المعرفة حول ما تشبهه الأشياء و الأشخاص، ما يقومون به، وكيف يستجييون إلى أفعال محددة. إن ما قد يبدأ بحركة عشو ائية ــ كالتلويح بملعقة خشبية و بالصدفة تصطدم بصندوق من الورق المقوى ـــينجم

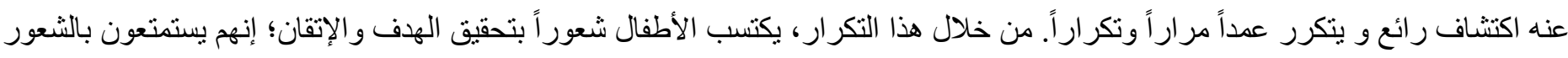
بكامل أجسامهم وصلابة الملعقة الخشبية والمقاومة المتينة للصندوق. في وقت لاحق، فإن هذه المعرفة التجريبية تؤدي بهم إلى محاولة القيام بسلسلة

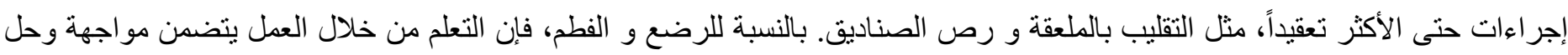
مشكلات مناسبة للرضع و الفطم (ما الذي يسبب هذه الضوضاء؟ كيف يمكنني تكرار ذلك؟) وفي هذه العطلية، يتم تشكيل أفكار هم عما يقوم به

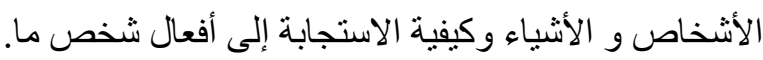
إن مقدمات الر عاية اللاتي تستندن في بر امجهن على مبادئ التعلم النشط يفهمن ويدعمن حسية الرضع و الفطم، ومنهج استخدام الجسم بالكامل للتعلم.

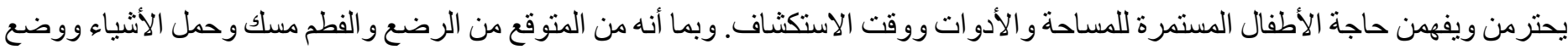

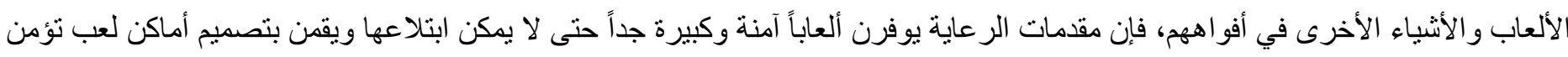

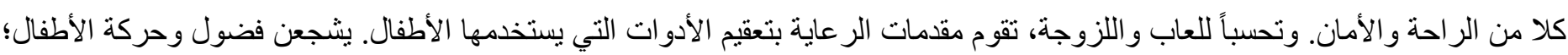

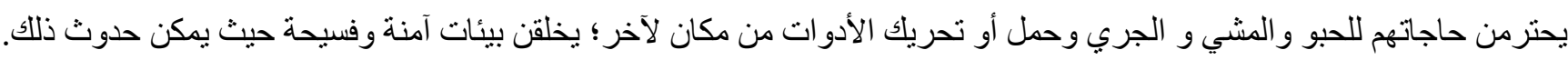

\section{• • يتطلم الرضع و الفطم لأنهم يريدون التعلم}

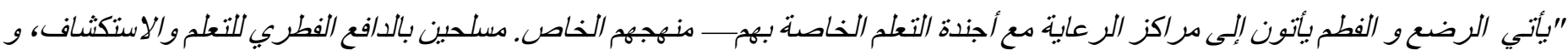

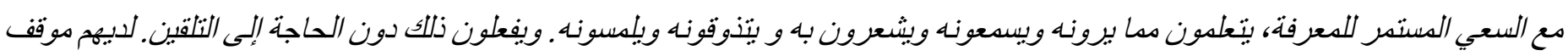

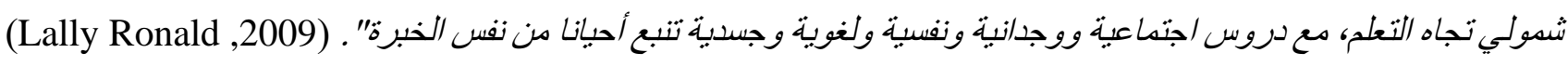

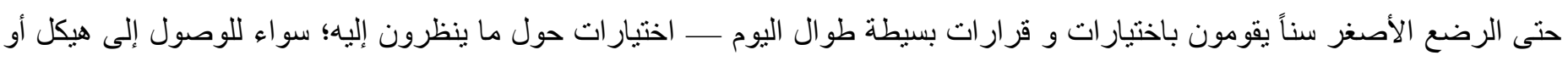

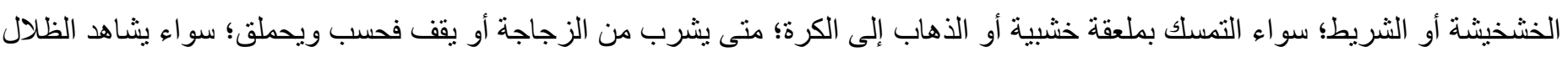

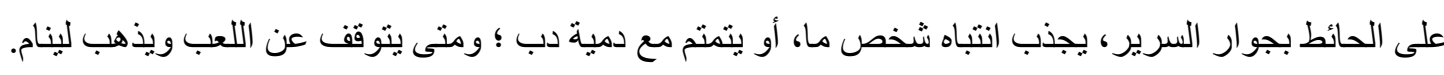
مع تطور الرضع في مرحلة الفطام، فإن الاختيارات والقرارات تزداد تعقيدا- سو اء الصعود إلى حضن مقدمة الرعاية أو الاستقر ار في وسادة

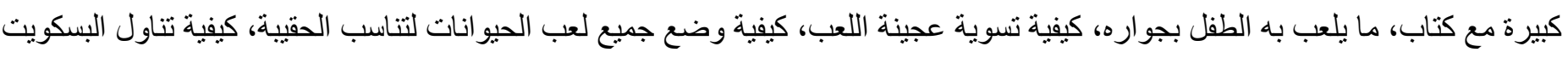
، ما هي الأشياء المريحة التي يصطحبها في وقت النوم (دمية ، بطانية، كتاب) ، ما يجب استخدامه لمسح أبي انسكابات، كيفية الوصول إلى الأشياء البعيدة. يشير الرضع والفطم إلى الأشخاص والأدوات والخبرات التي يفضلونها، يقررون ما سيكتشفونه، يعرفون كيفية حل المشكلات و إنجاز

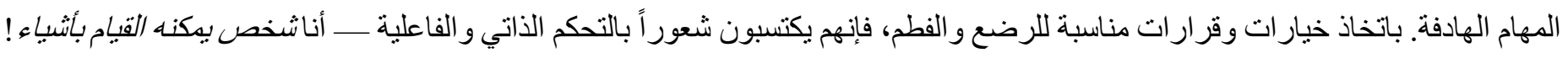
(بدلاً من شخص تُنجز له الأشياء). 
في البيئة الداعمة مع الفرص و التفاعلات المناسبة، يتصرف الأطفال الصغار جداً بمزيد من الضبط الذاتي و الاستقلال. يصبحون متشوقين لمعرفة

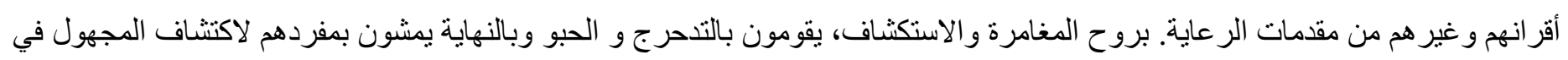

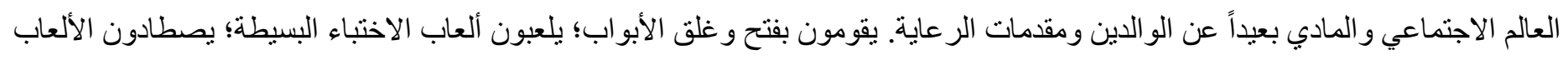
المختفية والأشخاص و الحيو انات الأليفة؛ يبحثون عن رفاق؛ يتسلقون أعلى وأسفل الدرج؛ ينظرون في الكتب مع أقر انهم؛ و يملؤون ويفرغون الرفوف و الصناديق و الحقائب و السلال. وأحياناً ما ثثثر جر أتهم مشاعر البهجة و الإتقان - رضيع يحبو وراء الأريكة ويعثر على كرة، أو فطيمان

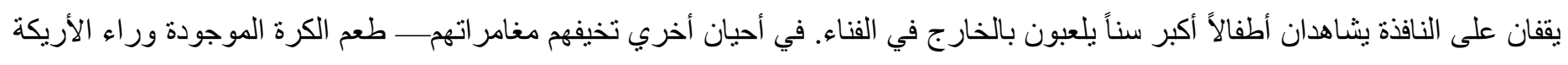
يبدو غريباً، كلب ينبح على الأطفال بالخارجـــ ويعودون بسر عة إلى الوالدين أو مقدمات الرعاية لتوفير الراحة و الطمائنينة. ولهذا السبب، فإنه في نفس الوقت الذي يصبح فيه الرضع و الفطم مستقلين وفضوليين، فإنهم يعتمدون أيضا على العلاقات الاجتماعية القوية مع مقدمات الرعاية الأساسيين في حياتهم لتأكيد استقلالهم الذاتي.

وقد لاحظ عالم النفس إريك إريكسون (Erikson,1960/1963) أن الفطيم يحتاج إلى دعم مقدمات الرعاية بدلاً من الانتقاد و الكبت و التوبيخ: " كما تشجعه بيئته على ' الوقوف على قدميه ' ، يجب أن تحمبه من الخبرات التعسفية من التوبيخ والثك المبكر." (يعتمد المتعلمون الصغار

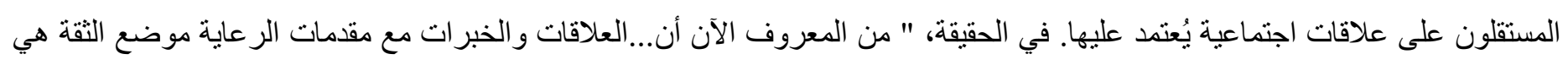
(أساس كل التعلم" (Lally, 2009). مع مرور الوقت، وفي روضة التعلم النشط يطور الأطفال الصغار جداً الرغبة والقدرة للعمل بثبات وأن يكون لهم تأثثر على الناس والأشياء.

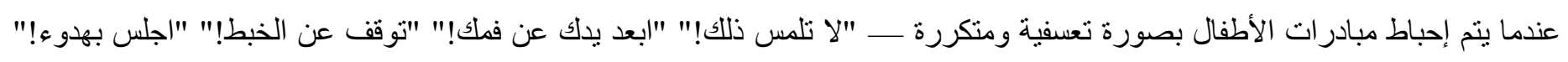
"ابتعد عن ذلك" "ابتعد من هنا" ـ يبدأ الأطفال في الثك في قدر اتهم الذاتية. على النقيض من ذللك، "عندما يشعر الأطفال أنهم يمكنهم الاعتماد

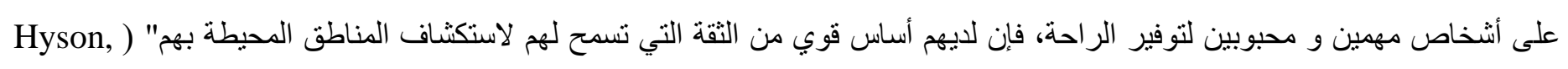

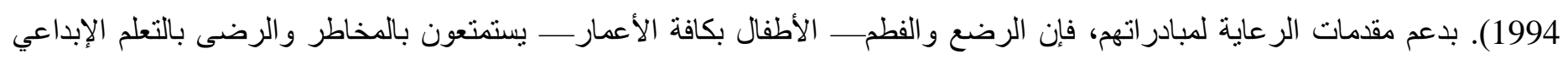
والحوار الاجتماعي. من الناحية العملية، فإن المقصود من ذلك أن مركز رعاية الطفل يدعم تطور الأطفال الصغار إذا تم تزويده بأدوات آمنة ومناسبة وصعبة وسهلة المنال لاستكثاف الأطفال. في مثل تلك الروضات، تدعم مقدمات الرعاية أولويات الأطفال وينتبهن إلى تفضيلات الأطفال وتلميحاتهم.

\section{يتواصل الرضع و الفطم بما يعرفونه}

"يأتي الأطفال إلى العالم مستعدين للتو اصل مع مقدمات الر عاية، المستعدين أيضا للتتو اصل معهم. يعتمد بقاءهم وصحتهم على قدرتهم في التو اصل

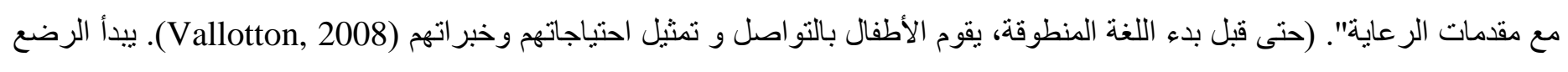

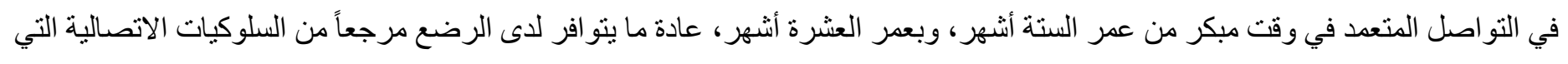
تثنمل الألفاظ والإيماءات مثل الإشار ات و الأداء. ببلوغ الثنهر الثاني عثر فإنهم يتعمدون استخدام الإيماءات للتأثثر على الحالة النفسية للأخرين

لتغيير مز اج مقدمة الر عاية من الاستهجان أو القلق إلى الابتسامة (Tomasello, Carpenter, \& Liszkowski, 2007).

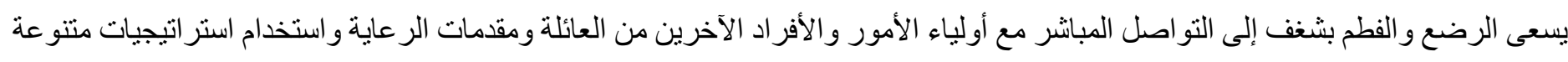

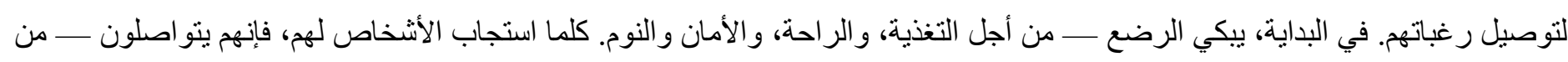

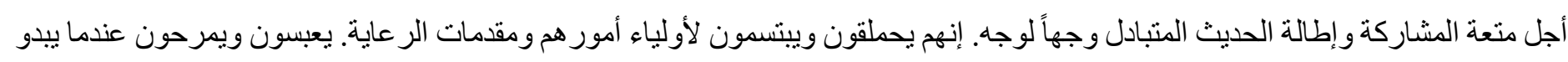

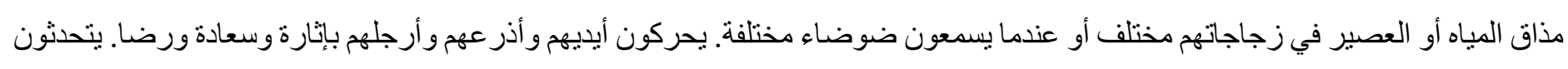
بنعو مة مع الأشخاص المفضلين و الحيو انات الأليفةو الألعاب. يبدؤون في التمتمة وتكرار الأصو ات المتحركة و الساكنة التي يسمعونها في المحادثات. تدريجياً، فإن هذه التمتمة تأخذ شكل تصريفات و إيقاعات الكلام البشري حيث أنهم يحاولون الانضمام إلى محادثات متبادلة في المحادثات الاجتماعية. 
من المثير للاهتمام، فإن سماع الأطفال المعاقين أو الأطفال من الو الدين الصم الذين يتعرضون للغة الإشارة منذ الولادة ييدؤون أيضاً "بالثرثرة" بأصابعهم قبل أن تأخذ الإشار ات أشكال العلامات التقليدية (Buckley, Bird, \& Sacks, 2006).

عندما يبدأ رضيع أو فطيم في التحدث، تكون اللغة الأولى مبسطة ومختصرة. يسمع الأطفال الصغار ويفهمون اللغة لوقت طويل قبل أن يتمكنو امن نطقها بأنفسهم في شكلها النحوي القياسي. في هذه الأثناء، يقومون بربط الأصوات و الإشار ات ونات و الكلمة بأسلوب ملائم لهم.

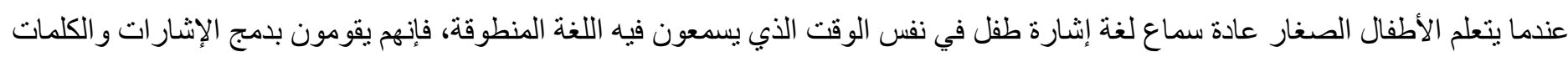

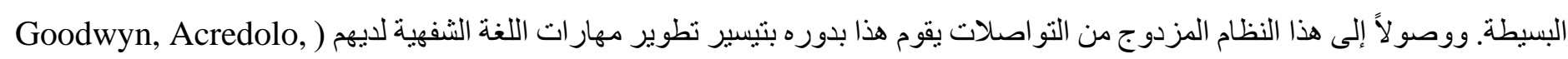

.(\& Brown, 2000

من خلال توصيل ما يشعرون به ويكتشفونه إلى مقدمات الر عاية المرسلين و المستقبلين، يدخل الرضع و الفطم إلى الحياة الاجتماعية الدائمة للمجتمع،

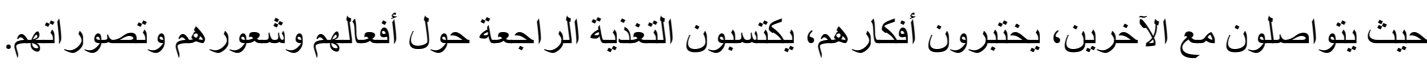

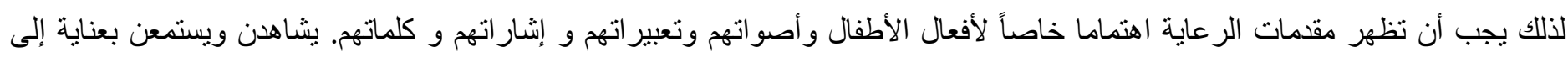
الأطفال ويمنحنهن مساحة كافية في المحادثة للتعبير عن أنفسهم بأسلوبهم الخاص. يمكنّ الأطفال من كلا من سماع اللغة ومن المشاركة كثركاء فاعلين في التواصل.

يريد الرضع و الفطم التواصل وتوصيل المعنى. بقدر ما يتم دعم هذه الرغبات باحتر ام، كلما أصبحو ايتواصلون بشكل أفضل. إن بر اعة الأطفال

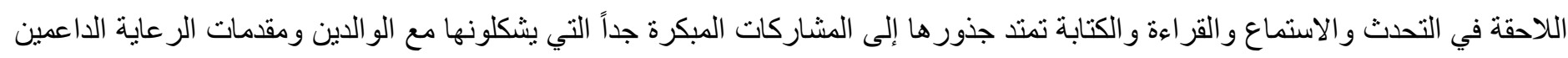

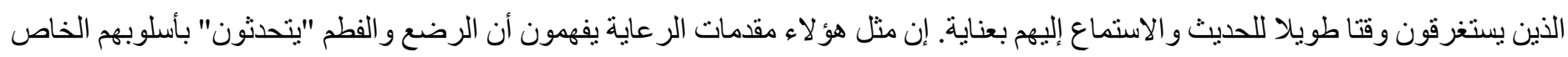
ويريبون التحدث، حتى قبل أن يبدأوا في استخدام الكلمات المناسبة.

\section{يتعلم الرضع والفطم في سياق العلاقات موضع الثقة}

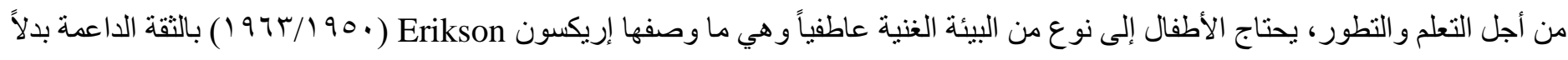

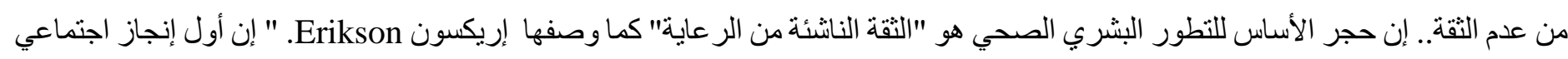
للرضيع هو قدرته على نرك و الدته بعيداً عن نظره دون قلق أو غضب لا مبرر له، حيث أصبح لديه اليقين الداخلي فضلا عن إمكانية التنبؤ

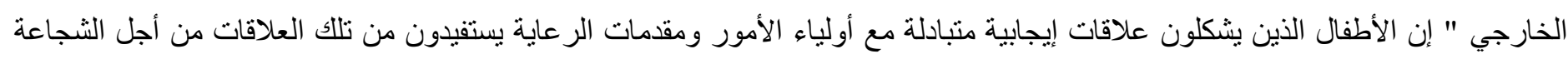
لاستكثاف العالم بعيداً عن رعاية مقدمات الرعاية. لإنائ.

بالر غم من أن الرضع و الفطم لديهم دو افع ذاتية قوية للتعلم بكامل أجسادهم وبكافة حواسهم ولتوصيل ما يعرفونه، إلا أنهم يعتمدون على إيجابية ودفء العلاقات موضع الثقة حتى يستطيعوا القيام بذللك. ينبغي على أولياء الأمور أن " يكونو ا قادرين على تمثيل قناعة عميقة و إلى حدما جسدية،

$$
\text { بأن هناك مغزى لما يقومون به " }
$$

ومن خلال أفعالهم، عندما ينقل أولياء الأمور ومقدمات الرعاية اعتقادا متأصلاً في قيمة الأطفال الجوهرية، يطور الأطفال شعور اً متمكناً من التقة، و التوصب البشري، و رغبة لاستكثاف العالم. لذلك فإن مقدمات الر عاية يلعبن دور اً مهماً جداً في التأثثر على كيفية اهتمام الأطفال برؤية عالمهم

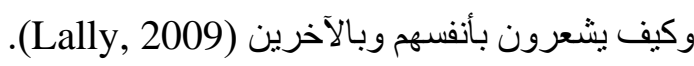


من خلال الثعور العميق، والتفاعلات المنبادلة المضبوطة بدقة، يطابق أولياء الأمور ومقدمات الرعاية مشاعر الطفل ومستوى الاهتمام لنقل احساسهم بما يشعر به الطفل. يتعلم الطفل الثقة في أن مقدمة الرعاية سوف تستجيب له وفي الوقت نفسه، يثق الطفل في نفسه بأنه سيحصل على استجابة مرضية من مقدمات الر عاية، بهذه الطريقة، يكتسب الطفل ثقة. بـان. إن الأطفال الذين بشعرون في العلاقات بالثقة، ربما يعرفون إلى حد ما أن أولياء الأمور و المعلمات سوف يدعمونهم من خلال تحديات و إنجاز ات جديدة - انظر ! استطيع أن أقف بمفردي! - وتوفير الر احة والتو اصل عندما تصعب الأمور - ساعدوني! أسمع ضجيج مخيف! وكما كتب Rodd) Jillian,1996) على الفور وبإيجابية وباستمر ار. إذا تعلم الرضع أنه يتم تقدير هم و العناية بهم واحتر امهم كأعضاء مهمين في المجمو عة، سيكون لديهم أساس قوي يمكن من خلاله الاستكثاف و التعلم عن العالم بثقة".

بدون العلاقات موضع الثقة، يمكن أن يخسر الأطفال الإر ادة للحياة. لقد اكتشف كلاً من (Spitz Rene,1945) و الباحث في تعلم الحيوان Harlow) Harry,1958) أيضاً، بالر غم من نوفير احتباجاتهم من الغذاء و المأوى و العناية الجسمية بشكل كاف.

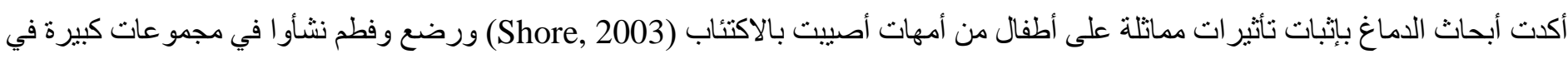
دور أيتام أوروبا الثرقية بها نقص في الموظفين (Talbot, 1998). قد كثفت خرائط النشاط الكهربائي للاماغ أن الضغط النفسي يمكن أن يعوق النشاط الصحي للاماغ، وتحت الظروف القاسية الممتدة من الضغط النفسي والجسمي، قد يقف الدماغ تماماً. بدون وقود علاقات الثقة، قد ينغر الأطفال بمشاعر الخوف والحزن والأسى ويصبحون بشكل متز ايد سلبيين وغير قادرين على القيام بأي إثـارة لطلب المساعدة. ومع "العلم" بأن الآخرين لا يستجييون إلى محاو لاتهم للتو اصل ، فإنهم ينسحبون من العالم "ويفشلون في التطور ". على النقيض من ذللك، فإن علاقات الثقة تعزز التطور الجسمي والصحي و العاطفي. علاوة على ذللك، فإن كل علاقة ثقة تؤدي إلى أخرى؛ إن الطفل الذي لديه على الأقل علاقة واحدة آمنة من المرجح أن بطور علاقات آمنة مع أثخاص أخربن في العالم، مثل الأجداد ومقدمات الرعاية والأطفال الآخرين المألوفين، ومتخصصي رعاية الأطفال والتربية. إن علاقات الرضع مع الأشخاص الآخرين، مثل مقدمات الرعاية ، لا تعد مُهدة للعلاقة الوطبية بين الأم والطفل بل (بعتق) أنها تساهم في تنمبية شعور الأطفال بالثقة في العالم والأشخاص به (Rodd, 1996, p.30) ثم يحدث التعلم النشط في سياق اجتماعي مكثف حيث تكون به علاقات الثقة ضرورية. أظهر البحث بين علماء الدماغ و علم النفس المعرفي أن المؤشر ات الاجتماعية تساعد على إبراز ماو منى يتعلم الأطفال (Meltzoff et aI., 2009). أظهرت الدراسات أن التعلم المبكرة يحدث بسهولة

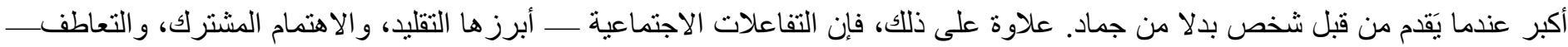
تيسر الفهم المعرفي للطفل الصغير. استتاداً إلى البحوث التر اكمية في العقود الأخيرة، فقد عرف علماء نفس التطور ومتخصصو الصحة النفسية أن Hauser-Cram, Warfield, ) فاعلية مر اكز الرعاية المبكرة تجمع بين التدريس والرعاية، بجانب الدعم العاطفي وتيسير التعلم بشكل متزامن (Shonkoff, \& Krauss, 2001 . بعبارة أخرى، "فإن التعلم و الحب ليس متباعدان كما كنا نظن من قبل" (Lally, 2009). نظر اللضرورة المطلقة لعلاقات الثقة من أجل التعلم والتطور، كيف تبني مقدمات الر عاية وتحافظ على مثل هذه العلاقات مع الأطفال في رعايتاهن؟؟ وصفت (Owen ,Margaret T.,1996) أنو اع السلوك الذي أظهرته مقدمات الرعاية المشاركون في علاقات الثقة مع الأطفال الصغار جداً: •العساسية لعدم توتير الطفل: تستفيد مقدمة الرعاية من لعب الطفل. •الاتتباه الإيجابي: تستمتع مقدمة الرعاية بأفعال واستكثافات الطفل. •نقص السلبية: نوصل مقدمة الرعاية الدفء و الاحتر ام. •المشاعر المشتركة: : تقدر مقدمة الرعاية مشاعر الطفل، من السرور إلى الإحباط. •الاتصال الجبسي الإيجابي: لمقدمة الرعاية تفاعلات جسدية دافئة مع الطفل، منها العناق و الحضن و الحمل و التمسيد و الاحتضان من الخلف. 
•التجاوب اليقظ: تتجاوب مقدمة الر عاية بسر عة إلى إثشار ات الطفل وأساليبه، وتو اصل وحديث الطفل؛ تعطي الطفل كامل اهتمامها. •التحفيز : تتحدث مقدمة الرعاية مع الطفل، تخبره بما سيحدث بعد ذلك، تشجعه على حل المشكلات، وتقر أل له. إن هذه السلوكيات التي تبني التقة والتبادل الاجتماعي الحيوي، تشكل أسلوب تفاعل مقدمات الرعاية مع الرضع و الفطم طو ال اليوم. إن الحاجة إلى تشكيل و الحفاظ على علاقات ثقة مع الرضع و الفظم في رعايتها تشكل كل جانب من دور المعلمة وتوجه القرار ات التي يتخذها

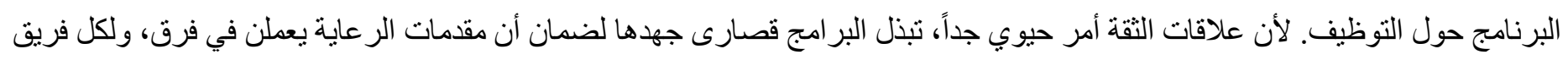
عضوة مسؤولة عن مجمو عة صغيرة من الأطفال تبقى في رعايتهم منذ العام الأول و التالي وحتى طو ال مدة التحاقهم بمركز الرعاية. إن استمر ارية الر عاية التي تنشأ من هذا التنظيم تدعم تطور علاقات الثقة بين الطفل ومقدمة الر عاية، وبين مقدمة الرعاية و الأسر ، وبين مقدمات الر عاية أنفسهن.

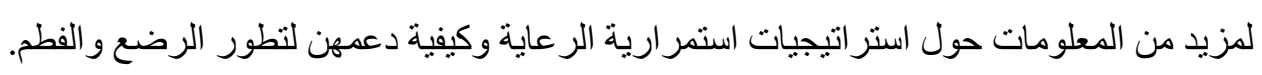
يتفاعل الرضع و الفطم مع الأشخاص ويتعاملون مع الأدوات، إنهم يشكلون مرجع من المعرفة حول ما تشبهه الأشياء و الأشخاص، ما يقومون بهاه،

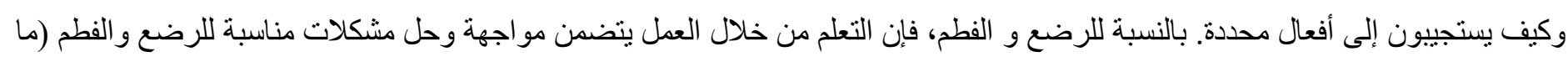
الذي يسبب هذه الضوضاء؟ كيف يمكنني تكر ار ذلك؟) وفي هذه العملية، ينم تشكيل أفكار هم عما يقوم به الأشخاص و الأشياء وكيفية الاستجابة إلى لى أفعال شخص ما. إن مقدمات الر عاية اللاتي تستندن في بر امجهن على مبادئ التعلم النشط يفهمن ويدعمن حسية الرضع و الفطم، ومنهج استخدام الجسم بالكامل للتعلم.

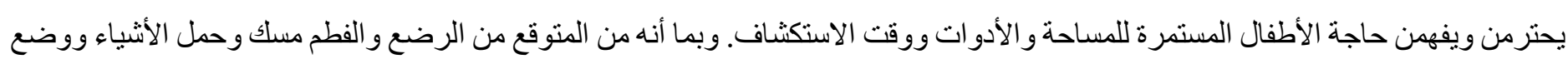

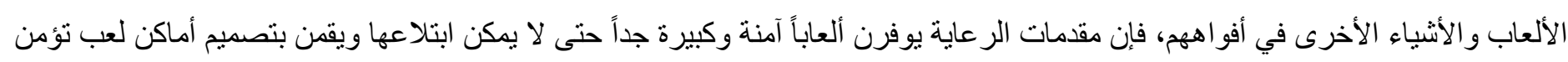

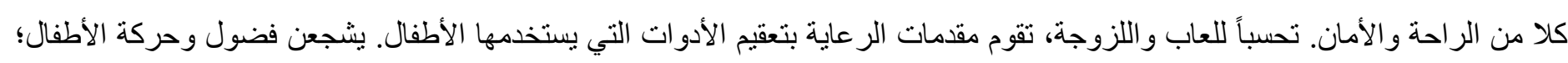
يحترمن حاجاتهم للحبو و المشي و الجري وحمل أو تحريك الأدوات من مكان لآخر ؛ يخلقن بيئات آمنة وفسيحة حيث يمكن حدوث ذللك. للابل

\section{• يتعلم الرضع و الفطم لأنهم يريدون التعلم}

للرضع و الفطم دو افع ذاتية قوية للتعلم و الاستكثاف ـ ـبطريقتهم الخاصة، وبوسائلهم الخاصة. يتطور التعلم من نشاطهم المحفز في حد ذاته. ليس لأحد أن يأمر هم بالتعلم أو حثهم للعمل. إن اختيار اتهم ور غبتهم في الاستقلال الذاتي والمبادرة تتولى ذلك الأمر! في الواقع، بالملاحظة المنزلية

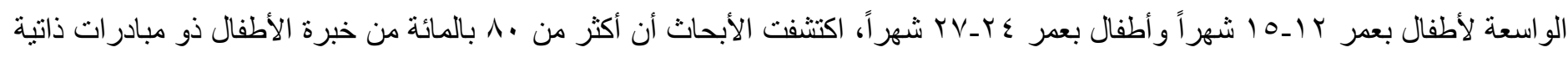

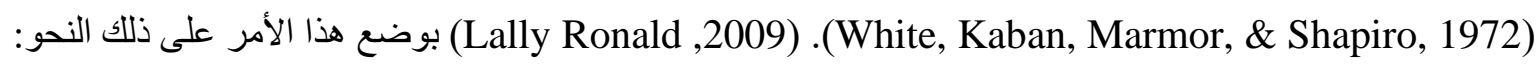

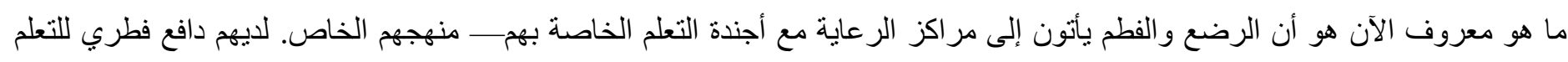

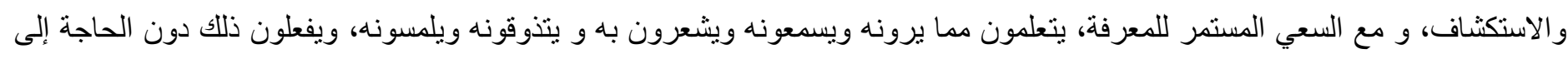
التلقين. لايهم موقف شمولي تجاه التعلم، مع دروس اجتماعية ووجدانية ونفسية ولغوية وجسدية تتبع أحيانا من نفس الخبرة.

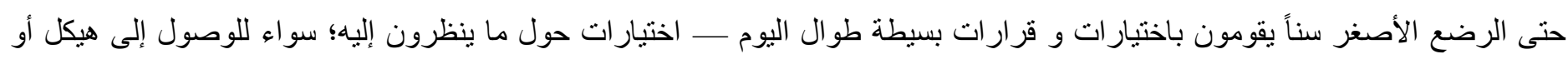
الخشخيشة أو الثريط؛ سواء التمسك بملعقة خشبية أو الذهاب إلى الكرة؛ منى يشرب من الزجاجة أو يقف فحسب ويحملق؛ سواء يشاهد الظلال

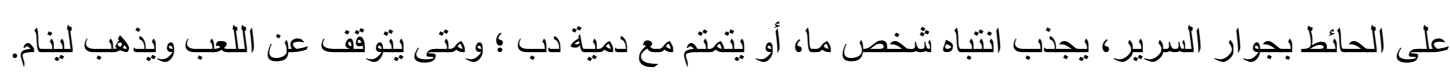

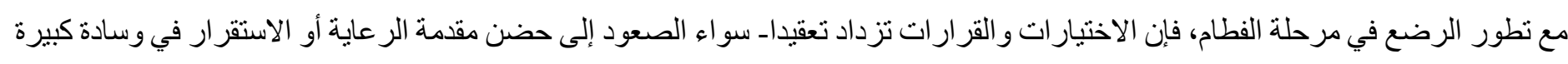
مع كتاب، ما يلعب به الطفل بجواره، كيفية تسوية عجينة اللعب، كيفية وضع جميع لعب الحيوانات لتناسب الحقيبة، كيفية تناول البسكويت الرفيق، ما هي الأشياء المريحة التي يصطحبها في وقت النوم (دمية، بطانية، كتاب) ، ما يجب استخدامه لمسح أي انسكابات، كيفية الوصول إلى الأشياء 
البعيدة. يشير الرضع و الفطم إلى الأشخاص والأدوات والخبرات التي يفضلونها، يقررون ما سيكتشفونه، يعرفون كيفية حل المشكلات و إنجاز المهام الهادفة. وباتخاذ خيار ات وقرار ات مناسبة للرضع و الفطم، فإنهم يكتسبون شعور اً بالتحكم الذاتي و الفاعلية. في البيئة الداعمة مع الفرص و التفاعلات المناسبة، يتصرف الأطفال بمزيد من الضبط الذاتي والاستقلال. يصبحون متشوقين لمعرفة أقرانهم و غير هم من مقدمات الرعاية. بروح المغامرة والاستكثاف، يقومون بالتدحرج و الحبو وبالنهاية يمشون بمفردهم لاكتشاف المجهول في العالم الاجتماعي و المادي بعيداً عن الو الدين ومقدمات الرعاية. يقو مون بفتح و غلق الأبو اب؛ يلعبون ألعاب الاختباء البسيطة؛ يصطادون الألعاب المختفية

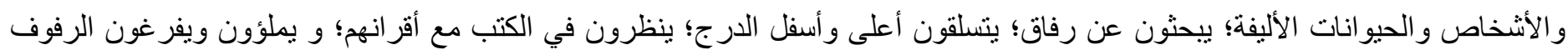
و الصناديق و الحقائب و السلال. وأحياناً ما تثير جر أتهم مشاعر البهجة والإتقان - رضيع يحبو وراء الأريكة ويعثر على كرة، أو فطيمان يقفان

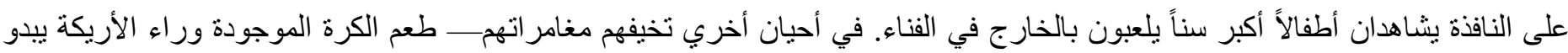

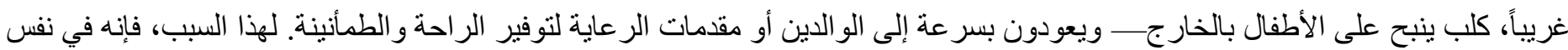

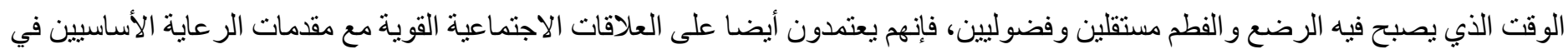
حياتهم لتأكبد استقلالهم الذاتي. لاحظ عالم النفس إريك إريكسون (Erikson,1960/1963) أن الفطيم يحتاج إلى دعم مقدمات الرعاية بدلاً من الانتقاد والكبت و التوبيخ: " كما تتجعه بيئته على 'الوقوف على قدميه ' ، يجب أن تحميه من الخبرات التعسفية من التوبيخ والثكك المبكر." (يعتمد المتعلمون الصغار المستقلون

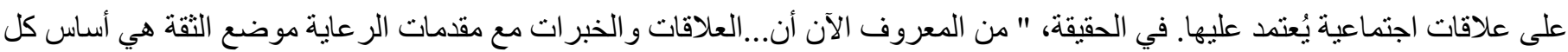
التعلم" (Lally, 2009). مع مرور الوقت، وفي روضة التعلم النشط يطور الأطفال الصغار جداً الرغبة والقدرة للعمل بثبات وأن يكون لهم تأثير على الناس والأشياء. عندما يتم إحباط مبادر ات الأطفال بصورة تعسفية ومتكررة ـ- "لا تلمس ذلك!" "ابعد يدك عن فمك!" "توقف عن الخبط!" "- يبدأ الأطفال في الثنك في قدر اتهم الذاتية. على النقيض من ذللك، "عندما يشعر الأطفال أنهم يمكنهم الاعتماد على أثنخاص مهمين و محبوبين لتوفير الراحة، فإن لديهم أساس

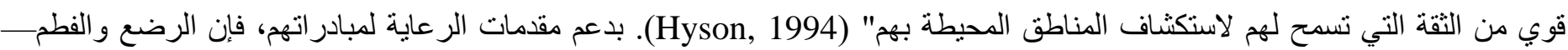
الأطفال بكافة الأعمار ـ- يستمتعون بالمخاطر و الرضى بالتعلم الإبداعي و الحوار الاجتماعي. لإسي. من الناحية العملية، فإن المقصود من ذلك أن مركز رعاية الطفل يدعم تطور الأطفال الصغار إذا تم تزويده بأدوات آمنة ومناسبة وصعبة و سهلة المنال لاستكثاف الأطفال. في مثل تلك الروضات، تدعم مقدمات الر عاية أولويات الأطفال وينتبهن إلى تفضيلات الأطفال وتلميحاتهم. بدلاً من محاو لة توجيه الأطفال لتعلم أثنياء محددة في أوقات محددة، تقوم مقدمات الرعاية بدعم وبناء اختيار ات الأطفال ومبادرات التعلم ذات الدافع الذاتي. 
Buckley, S. J., Bird, G., \& Sacks, B. (2006). Evidence that we can change the profile from a study of inclusive education. Down Syndrome Research and Practice, 9(3), 51-53. doi:10.3104/essays.294

French, G., \& Murphy, P. .(2005). Once in a lifetime.. Early childhood care and education for children from birth to three. Dublin, Ireland: Barnardos National Children's Resource Centre

Goodwyn, S. W., Acredolo, 1. P., \& Brown, C.A. .(2000). Impact of symbolic gesturing on early language development. Journal of Nonverbal Behavior, 24(2), 81-103.doi: 10.1023/A,1006653828895

Harlow, H. (1958). The nature of love. American Psychologist, 13(12), pp. 673--685. doi,10.1037/h0047884

Hauser-Cram, P., Warfield, M. E" Shonkoff, J. P., \& Krauss, M. w. (2001). Children with disabilities, A longitudinal study of child development and parent well-being. Monographs of the Society for Research in Child Development, 66(3, Serial No. 266). doi,10.1111/1540-5834.00150

Hyson, M. C. (1994). The emotional development of young children. Building an emotion- centered curriculum. New York: Teachers College Press.

Lally Ronald ,(2009). Infant/Toddler Caregiving. Published by California Department of Education Meltzoff, A. N., Kuhl, P. K., Movellan, J., \& Sejnowski, T. J. (2009). Foundations for a new science of learning. Science, 325(5938),284-288. doi:10.11261 science.1175626

Owen, M. T. (1996, November). Symposium on early child care and attachment: Findings from the National Institute of Child Health and Human Development Study of Early Child Care. Report of the Attachment Task Force. Annual Conference of the National Association for the Education of Young Children, Dallas, TX.

Rodd, J. (1996). Undemanding young children's behavior: A guide for early childhood professionals. New York: Teachers College Press

Schiller, P. .(2008). Start Smart.. Building brain power in the early years. Boston: Gryphon House Shore, R. (2003). Rethinking the brain: New insights into early development (Rev. ed.). Washington, DC: Families and Work Institute.

Siegel, D. J. (1999). The developing mind. Toward a neurobiology of interpersonal experience. New York: Guilford Press

Spitz, R. (1945). Hospitalism: An inquiry into the genesis of psychiatric conditions in early childhood. Psychoanalytic Study of the Child, 1, 53-74

Talbot, M. (1998). May 24. Attachment theory: The ultimate experiment. The New York Times Magazine, pp. 24-30, 38, 46, 50, 54.

Tierney, A., \& Nelson, C. A. .(2009). Brain development and the role of experience in the early years. Zero to Three, 30(2), 9-13. 
Tomasello, M., Carpenter, M., \& Liszkowski, U. (2007). A new look at infant pointing. Child Development, 78(3), 705-722. doi:10.1111/j.1467-8624.2007.01025.

Vallotton, C. (2008). Infants take self-regulation into their own hands. Zero to Three, 29(1), 29-34

White, B., Kaban, B., Marmor,J., \& Shapiro, B, (1972). Child-rearing practices and the development of competence: Final report (Grant No. CO-9909 A12). Washington, DC Office of Economic Opportunity, Head Start Division 